\title{
Crisis Communication at the Fukushima Accident and the Concept of Crisis Management
}

\author{
-What is the information dissemination for?-
}

\author{
Kansai University, Shoji Tsuchida
}

\begin{abstract}
This commentary discusses the crisis communication that took place during the severe accidents experienced by the Tokyo Electric Power Company at its Fukushima Daiichi Nuclear Power Plant in the aftermath of the 2011 Great East Japan earthquake. Crisis communication is conducted to exchange information between the actors who are responding to a crisis and the public. The commentary first defines the term "public" in this context and explains why crisis communication is necessary. After that, it identifies problems that occurred in relation to crisis communication during the Fukushima Nuclear Accident according to the idea that safety, rather than security, is the top priority when responding to a crisis.
\end{abstract}

\section{Introduction}

The 2011 Great East Japan earthquake that occurred on March 11 and the subsequent tsunami ravaged parts of east Japan. In addition, a complete loss of external and emergency AC power at the Fukushima Daiichi Nuclear Power Plant operated by Tokyo Electric Power Company (TEPCO) resulted in severe accidents (hereinafter referred to as the "Fukushima Nuclear Accident"). With more than seven months having passed since the accident was triggered, this commentary discusses the initial crisis management in retrospect, with a particular focus on crisis communication.

\section{Crisis Communication}

(1) What is crisis communication?

Putting details aside, the Fukushima Nuclear Accident was literally a crisis involving severe accidents. Crisis communication is the exchange of information with the public in response to a crisis (severe accidents). One of the most difficult tasks to perform during a crisis is to perceive the reality of the situation accurately based on proper assessments. The difficulty involved in taking on-site measurements is not the only reason. Under difficult circumstances, people's perception of reality is also distorted by human (psychological) factors. For instance,

DOI : 10.15669/fukushimainsights.Vol.1.224

() 2021 Atomic Energy Society of Japan. All rights reserved.

Originally published in Journal of the Atomic Energy Society of Japan (ISSN 1882-2606), Vol. 54, No. 3, p. 181-183 (2012)

in Japanese. (Japanese version accepted: November 27, 2011) 
on the first day of a war, $80 \%$ of reports from the battlefront are said to provide incorrect information.

For this reason, crisis communication is not limited to the actors who are directly responding to a crisis simply reporting the on-site situation to the public. Essentially, the public need to communicate with these actors to ensure that the latter perceive the reality of the situation and make on-site judgments objectively.

(2) Who are the public in relation to crisis communication?

As a counterpart in the exchange of information with the actors directly responding to a crisis, the public can be classified as follows in relation to crisis communication.

(1) General public: By definition, the term "public" refers to people in general.

(2) Press: As the mass media is well developed today, the press represents the general public by serving as an interface for information exchanges between them and the actors responding to a crisis.

(3) Administrative bodies: Administrative bodies exercise authority in various fields on different levels on behalf of the general public. The central (national) government, prefectural governments, and municipal governments on local levels work closely together. It is important to note, however, that these bodies are separate counterparts in relation to the actors responding to a crisis and they each require an adequate amount of individual information exchanges.

In the case of the Fukushima Nuclear Accident, TEPCO and the Nuclear and Industrial Safety Agency (NISA) seem to have, in their capacity as the on-site actors, exchanged information with the Prime Minister's Office, which was ultimately responsible for the response to the accident. However, it seems likely that little information was exchanged with the prefectural and municipal governments. The adequacy of the information that the national government exchanged with prefectural and municipal governments has yet to be verified.

(4) Affiliated companies and industry peers: Nuclear power in Japan is not carried out entirely by the utility companies alone. Their operations are sustained by their partners, second-tier and third-tier contractors, and so forth. Needless to say, information exchanges among these companies are vital during any crisis. Moreover, a large part of the resources and capacity that would normally be expected becomes unavailable during a crisis. To make up for this loss, information must be exchanged among otherwise unfamiliar affiliated companies and industry peers.

(5) Research and development institutes (and relevant professionals) involved in other fields: A crisis is an abnormal situation that would not normally be expected to occur. Naturally, research findings from other fields may prove effective in helping to deal with such a crisis. A situation that is abnormal for actors in one field may be usual or expected for actors in another field. The more abnormal a given situation is, the more effective exchanges with research and development institutes from other fields may prove to be.

(6) Overseas counterparts of the abovementioned stakeholders ((1)-(5)): In today's global society, crisis communication regarding nuclear accidents must be conducted with other countries no differently to how it is conducted in our own country.

Media coverage of the Fukushima Nuclear Accident suggests that TEPCO, as the primary actor, actively sought to engage in crisis communication with supervisory administrative bodies. Perhaps in line with instructions issued by these bodies, TEPCO formally engaged in crisis communication to a certain degree with the press, as well. Nevertheless, the extent and effectiveness of the crisis communication that TEPCO conducted directly with local residents, municipalities and other local administrative bodies that deal closely 
with residents, affiliated companies, industry peers, research and development institutes from other fields, and the public in other countries has yet to be verified.

\section{Why is Crisis Communication Necessary?}

Crisis communication must be conducted by the actors responsible for responding to a crisis for the following reasons.

(1) To fulfill moral obligation: The actors are held accountable for having caused an accident and disturbance in society. Naturally, they have an obligation to explain the situation to the public. Crisis communication is carried out solely out of moral obligation if the resulting crisis can be contained by the actors. Crisis communication becomes crucial for the reasons described below in any crisis that grows beyond the control of the actors to cause extensive damage and impact.

(2) To gain the public's understanding: To prevent harmful rumors and ensure that public opinion is shaped based on reasoning that withstands criticism, the public should be asked to understand a crisis based on an adequate amount of accurate information. To this end, the actors must provide the public with the information necessary to gain a proper understanding as well as respond to any feedback from the public regarding the information provided.

(3) To save the public: If the crisis also affects the public, information on hazards and evacuation requirements must be swiftly disclosed to the public. The actors must also swiftly accept and respond to any information shared by the public regarding possible hazards associated with the crisis.

(4) To request the public's support: A serious crisis can no longer be handled solely by the actors directly responding to it. In such a situation, support must be sought from the wider public (the whole country or even all of humanity). During such crisis communication, it is important to specify the form of support that is being requested from the public while providing clear information to the intended recipients.

In the crisis communication prompted by the Fukushima Nuclear Accident, TEPCO solicited support only from the national government as their legal superordinate decision-making body. According to media coverage, TEPCO did not solicit support from anyone else. The operations required to deal with a crisis are not envisaged in routine work. The actors must be open to the possibility that others may have superior skills and knowledge in relation to handling such extraordinary operations. Crisis communication can prove effective in helping to overcome a crisis when the form of support being requested is specified. For instance, support could be requested from smaller companies, research and educational institutes, and a wide range of other potential partners to locate heavy machinery that is resistant to a specified level of radiation so that remote operations can be performed without any of its electronic units malfunctioning.

\section{The Issue of the "Unexpected": Two Dimensions of Safety Measures}

During the initial phase of the Fukushima Nuclear Accident, the actors directly responding to the accident and other concerned experts often described the accident as "unexpected." The problems inherent in describing a crisis as something unexpected are pointed out based 
on the two interrelated concepts of security and safety.

\section{Security and Safety}

The Japanese word "ANZEN" carries at least two meanings ").

One meaning is "security," which can be defined as the minimized probability of accidents and disasters. Basically, the focus is placed on the prevention of these undesired events.

The other meaning is "safety," which can be defined as the minimizing of damage from any accidents and disasters that take place.

Prior to the Fukushima Nuclear Accident, nuclear ANZEN measures in Japan had been excessively focused on security. Safety measures aimed at the mitigation of severe accidents may have neglected what needed to be done if a severe accident took place. In other words, these measures would inevitably be criticized for neglecting safety. Such neglect is symbolized by the fact that the term "unexpected" was used during the crisis.

\section{Any Party that Resorts to Saying "That Was Unexpected" Is Incompetent}

Tomio Kinoshita classified unexpected circumstances into the following five categories ${ }^{2}$ : (1) meteorite impacts and other extremely rare events; (2) circumstances that are considered likely only by the minority in a relevant discipline; (3) circumstances subjectively deemed unlikely by directly involved actors due to their overconfidence or the like; (4) circumstances classified as unexpected as a result of a tradeoff with costs, political considerations, and other external factors; and (5) circumstances whose likelihoods were unnoticed by directly involved actors due to a lack of diligence or imagination. Kinoshita concludes that, in the proper sense of the word, unexpected events only belong to Category (1) and that the rest do not qualify. In any case, the most important issue is the reality that severe accidents took place. The expression "unexpected" only has worth as an indication that the security side of ANZEN measures failed. It is useless in dealing with severe accidents that actually take place. As an illustration, imagine a commander who says during a war that an enemy's operations were unexpected. Such a remark would only serve as an acknowledgement of incompetence as the reason for the commander's resignation.

In response to a crisis that actually takes place, safety-oriented measures are necessary to minimize the resultant damage. Consequently, safety-related information must be shared in crisis communication.

Security-related information, including the question of what matters were genuinely unexpected, is only relevant after the end of a crisis during discussions concerning necessary future measures and who should be held responsible. Such information is utterly irrelevant in crisis communication during an ongoing crisis.

\section{What Type of Information Needs to be Shared and to What Extent in Crisis Communication?}

In crisis communication and other forms of communication, the type and extent of information to be shared depends on the ability of the intended recipients to comprehend the information. In other words, crisis communication is impossible without first assessing the comprehension capabilities of the intended recipients. To achieve the intended goal of crisis 
communication as described earlier, useful information must be shared with the intended recipients by inferring what they want to know and estimating their comprehension capabilities.

Any incomprehensible information that is shared will not reach the intended recipients properly. Worse still, such information is likely to be interpreted as an attempt to cover-up something or regarded as insincere or untrustworthy.

During the Fukushima Nuclear Accident, TEPCO and NISA probably did try to convey facts accurately by sharing information intended for media coverage. Nonetheless, it is apprehensive that the information was not even comprehensible to the journalists themselves. Communication requires adequate training and skills to enable information to be shared in accordance with the comprehension capabilities of the intended recipients. Unfortunately, there is a dire shortage of such talented personnel among entities dealing with nuclear energy.

\section{General References}

1) Emiko Kanoshima: Review concepts of safety, security, ANZEN (a Japanese word) and other relating words [in Japanese], Journal of Societal Safety Sciences, 1, 153-177, 2011.

2) Tomio Kinoshita: The Fukushima Nuclear Accident Discussed in Terms of Risk Sciences [in Japanese], Journal of the Atomic Energy Society of Japan, 53 (7), 465-472, 2011.

- H. Hirakawa, S. Tsuchiya, and T. Tsuchiya: Theory of Risk Communication [in Japanese], Osaka University Press, 2011.

- $\quad$ A. M. Howitt and H. B. Leonard (eds.): Managing Crises: Responses to Large-Scale Emergencies, CQ Press, 2009. 